\title{
IMAGINAÇÃO E IDENTIDADE NO PROCESSO NARRATIVO DE UMA PROFESSORA
}

\author{
IMAGINATION AND NARRATIVE IDENTITY IN THE PROCESS OF A TEACHER \\ LA IMAGINACIÓN Y LA IDENTIDAD EN EL PROCESO DE NARRATIVA DE UNA MAESTRA
}

Patrício Câmara Araújo*
Fabricia Teixeira Borges

\begin{abstract}
RESUMO
Este estudo teve como objetivo investigar a constituição identitária de uma professora, na narrativa de sua história de vida, considerando a imaginação no processo narrativo. Realizamos uma abordagem do self dialógico, por meio de entrevista narrativa e episódica, com uma professora de Biologia, do $6^{\circ}$ ao $9^{\circ}$ ano, de uma escola particular do Distrito Federal. Na pesquisa, utilizamos a análise temática dialógica da conversação com tabela e mapa semiótico. Reconhecemos que a identidade docente se constitui como processo dialógico do self com a participação da imaginação na elaboração da imagem que o indivíduo tem de si como herói de sua história. Os resultados sugerem uma diferença entre o posicionamento docente da professora e o seu contexto profissional, consequente da relação dialógica entre seus posicionamentos e o valor da afetividade na relação com os alunos.
\end{abstract}

Palavras-chave: Identidade. Narrativa. Imaginação. Docente. Self.

\begin{abstract}
This study aimed to investigate the constitution of a teacher's identity in the narrative of her life history, taking into account the imagination in the narrative process. We performed an approach based on the dialogical self theory, through a narrative and episodic interview with a 6th to 9th year biology teacher at a private school in the Brazilian Federal District. Throughout the research, we used the thematic dialogical analysis of the conversation with table and semiotic map. We recognize that a teacher identity is composed of a dialogical process of the self with the participation of the imagination in the development of the image that the individual has of him/herself as hero of his/her history. The results suggest a misalignment
\end{abstract}

\footnotetext{
Texto recebido em 12 de dezembro de 2016 e aprovado para publicação em 7 de junho de 2018.

*Doutor em Processos de Desenvolvimento Humano e Saúde pela Universidade de Brasília (UnB), professor de Filosofial Metodologia da Investigação Científica do IFMA - Campus Barreirinhas. Endereço: Rodovia MA-225, Km 4 - Povoado Santa Cruz, Barreirinhas-MA, Brasil. CEP: 65590-000. E-mail: patriciofilosofia@ifma.edu.br.

** Doutora em Psicologia pela UnB, professora no Instituto de Psicologia da UnB e orientadora no Programa de Pós-Graduação em Psicologia do Desenvolvimento e Escolar (PGPDE/UnB). Endereço: Campus Universitário Darcy Ribeiro ICC Sul, Brasília-DF, Brasil. CEP: 70910-900 E-mail: fabricia_borges@unb.br.
} 
between the teaching position developed by the teacher and her professional context, resulting from the dialogical relationship between her positions and the value of affectivity in the relationship with the students.

Keywords: Identity. Narrative. Imagination. Teacher. Self.

\section{RESUMEN}

Este estudio tuvo como objetivo investigar la constitución identitaria de una maestra en la narrativa de su historia de vida, considerando la imaginación en el proceso narrativo. Realizamos un enfoque del self dialógico, a través de una entrevista narrativa y episódica, con una profesora de Biología de la enseñanza básica secundaria, de una escuela particular del Distrito Federal. En la investigación, utilizamos el análisis temático dialógico de la conversación con tabla y mapa semiótico. Reconocemos que la identidad docente se constituye como proceso dialógico del self con la participación de la imaginación en la elaboración de la imagen que el individuo tiene de sí como héroe de su historia. Los resultados sugieren una desalineación entre el posicionamiento docente de la profesora y su contexto profesional, consecuente de la relación dialógica entre sus posicionamientos y el valor de la afectividad en la relación con los alumnos.

Palabras clave: Identidad. Narrativa. Imaginación. Docente. Self.

\section{INTRODUÇÃO}

constituição da identidade docente é relevante para compreendermos a
prática profissional do professor e como ele produz significados a partir dela
(Arvaja, 2016; Huang, 2014). Neste artigo, o objetivo é analisar o processo de constituição identitária docente na abordagem do self dialógico como processo psicológico (Akkerman \& Paulien, 2011; Arvaja, 2016; Henry, 2016; Huang, 2014; Hermans, 2015) em uma professora, por meio da construção da narrativa de sua história de vida (Atkinson, 1998; McAdams, 1993; Polkinghorne, 1988; Riessman, 1993).

Nesse sentido, inclui-se a contribuição da imaginação, entendida como processo de elaboração de imagens, a partir de experiências do indivíduo, mediadas semioticamente. A imaginação se expande por meio da experiência (Vigotski, 2014; Zittoun \& Cerchia, 2013; Zittoun \& Gillespie 2013; Cruz, 2015), e as imagens que são elaboradas combinam-se no processo narrativo, com significados vinculados a imagens. 
A identidade, a narrativa e a imaginação são três processos centrais em nossa pesquisa. Em nossa análise, investigaremos os processos psíquicos do indivíduo em relação aos processos socioculturais, a partir da perspectiva da Psicologia Cultural, (Valsiner, 2006; Wertsch, 1993). Reconhecemos o sujeito como conjunto das relações sociais nas quais ele internaliza significados. As relações são mediadas pela linguagem e produzem significados no processo dialógico entre as vozes na narrativa do indivíduo (Akkerman \& Paulien, 2011; Arvaja, 2016; Henry, 2016) e na constituição do seu psiquismo, ao internalizar as relações sociais (Sigardo, 2000; Vigotski, 2000).

No processo da imaginação, os elementos da experiência individual são transformados, pelo agrupamento subjetivo ou objetivo, e depois realizada a combinação complexa deles (Vigotski, 2014). Ao contar sua história, o indivíduo utiliza as memórias, de uma forma organizada, nas relações dialógicas com a produção de imagens vinculadas à emoção. Esta, por sua vez, implica envolvimento, relação e interação social. Assim, a narrativa da história de vida permite identificar significados relacionados à elaboração das imagens que o indivíduo tem de si e que participam da constituição de sua identidade.

\section{IDENTIDADE E SELF DIALÓGICO}

Hermans (2015) explica o self como construção complexa e social, além de culturalmente multifacetada. Além disso, esse autor também reconhece que a concepção de self está vinculada ao contexto social e tem caráter dialógico. A relação entre o self e o contexto social possibilita que um contribua para o desenvolvimento do outro. Essa teoria é a base de toda a discussão sobre o conceito de identidade que sustentamos em nossa pesquisa (Akkerman \& Paulien, 2011; Arvaja, 2016; Henry, 2016; Huang, 2014).

Akkerman e Paulien (2011), para explicarem a identidade docente, tomam como referência o self dialógico e consideram-na tanto unitária como múltipla, tão social como individual, além de contínua e descontínua. Para essas autoras, a identidade docente tem três caracterizaçôes: identidade como múltipla, de natureza social e descontínua, por não seguir uma sequência linear de eventos. Essa perspectiva apresenta uma concepção de identidade descentralizada e em constante transformação. A identidade, com base na teoria do self dialógico, é concebida, ao mesmo tempo, como complexa e coerente, estável e dinâmica. Isso é possível por meio de uma abordagem dialógica adequada para se referir ao self nessa visão mais dinâmica. 
Para Akkerman \& Paulien (2011), o self é composto de uma multiplicidade de posicionamentos dotados de vozes de suas próprias intençôes. Afirmam ainda que a identidade é múltipla, assim como há multiplicidade de posicionamentos. Os posicionamentos, por sua vez, estão em constante diálogo e conflito no self, por meio da criação de espaços de interlocução que possibilitem ao indivíduo a manutenção do seu sentido de si, através das negociações entre os diferentes posicionamentos. $\mathrm{O}$ espaço interlocucional descaracteriza o self como discurso interno, por envolver a multivocalidade como multiplicidade, diversidade e interação de vozes (Bakhtin, 2015).

No self, o sentido de continuidade é basilar, pois a questão é como garantir a noção de permanência ao longo do tempo. O que é possível pela narrativa como história de vida, porque esta possibilita preservar o sentido de continuidade através da temporalidade vivida, o que implica no posicionamento de si, apesar das mudanças pelas quais os indivíduos passam em cada situação, nas quais o self dinamicamente se posiciona em múltiplos lugares (Akkerman \& Paulien, 2011). Arvaja (2016) corrobora essa concepção ao reconhecer o caráter dinâmico e o sentido de continuidade da identidade no processo dialógico do self.

Nesse contexto, o processo de constituição identitária, a partir de uma abordagem dialógica dinâmica, permite entender a identidade como social. Contudo não basta apenas ocorrer uma interlocução entre as vozes para caracterizá-la como social, mas é importante que a interlocução seja endereçada como resposta ao outro, em interação dialógica. Akkerman \& Paulien (2011) comentam que o caráter social do self dialógico está no fato de os outros indivíduos ocuparem posições na multivocalidade, por meio de negociações entre as vozes. Vale ressaltar que a identidade como processo dialógico não se resume aos posicionamentos de si, porque os indivíduos precisam do encontro com os outros, por meio do qual se diferenciam e se constituem.

Nessa perspectiva, Arvaja (2016) apresenta um estudo em que reconhece que a narrativa individual participa da construção da identidade docente. Akkerman \& Paulien (2011) e Arvaja (2016) concordam que há uma negociação da identidade por meio da interlocução entre os múltiplos posicionamentos e que há uma mudança de posicionamento em cada encontro para responder ao outro. Arvaja (2016) comenta casos nos quais o processo de negociação não é bem-sucedido, por exemplo, quando não há uma relativa estabilidade entre o posicionamento profissional do docente e o seu contexto de trabalho. Isso o leva a não se perceber professor em sua atuação.

Anh (2013) explica que as negociações entre as múltiplas identidades do docente são constituídas por tensões, como contradições. Para Henry (2016), 
durante o estágio docente, as tensões que envolvem a construção da identidade do professor são mais agudas. Dessa maneira, uma das contradições entre as identidades pode ser encontrada na relação do docente com o estudante. Huang (2014) afirma que as contradiçôes não são problemas ou conflitos, mas tensões entre os elementos do sistema de atividade que estão presentes nas negociações entre as identidades do professor e do aluno. Assim, como as identidades são concebidas nos termos do processo dialógico com múltiplos posicionamentos de si (Akkerman \& Paulien, 2011; Arvaja, 2016) e a negociação entre elas é atravessada por contradições (Anh, 2013), as relaçóes entre os outros posicionamentos do indivíduo e o docente são tensas e constituídas de contradição.

As contradições estão presentes na relação entre as identidades docente e discente, que, por serem sociais, estão em constante dialética. Diante disso, em busca de um desejo por coerência e consistência, os indivíduos elaboram espaços dialógicos entre os posicionamentos para que a negociação se efetive, mesmo que por meio de contradições (Anh, 2013). Por isso, o licenciando, durante a graduação, pode se perceber estudante no contexto universitário, mas no estágio supervisionado se perceber como docente, em um posicionamento emparelhado ao do aluno, negociando com ele o posicionamento de professor, por meio de tensões na escola e em sala de aula. As negociações se dão na narrativa do indivíduo, elaborada a partir de suas experiências pessoais e sociais, apresentando tensões entre os posicionamentos (Arvaja, 2016). Na narrativa, encontramos o sentido do self negociado nas relaçôes dialógicas entre os posicionamentos, nas atividades cotidianas do docente e na narrativa que o self do docente elabora sobre sua história de vida (Anh, 2013; Arvaja, 2016).

As interações percebidas na narrativa ocorrem com diferentes posicionamentos, que podem combinar-se e mudar a hierarquia entre elas no self, a depender da situação da qual o indivíduo passe a fazer parte. Essas posições são dotadas de vozes que realizam interlocuções no self em espaços dialógicos narrativamente estruturados (Henry, 2016). A multivocalidade do self é constituída pela interlocução das vozes em um sistema dinâmico e complexo, com o movimento entre as vozes dos posicionamentos (Henry, 2016). Isso se dá por meio de negociações entre as vozes no self em um contexto, simultaneamente, múltiplo e unitário, contínuo e descontínuo, individual e social (Akkerman \& Paulien, 2011; Anh, 2013; Arvaja, 2016). No sistema dinâmico e múltiplo, a identidade está em cada posicionamento dotado de voz dentro da unidade do self e tem seu sentido de continuidade como condição de existência, por meio da narrativa da história de vida (Akkerman \& Paulien, 2011).

Huang (2014) considera que esse contexto e a atividade que nele o indivíduo realiza produzem sentidos no self. $\mathrm{O}$ autor afirma que o modo pelo qual o 
indivíduo produz significado sobre si é relacional. Se a dinâmica dialógica do self é constituída de relações sociais, então o self é social. O outro da interação social ocupa, desse modo, um posicionamento dotado de voz e intenção no self. Isso pode ser encontrado na narrativa do indivíduo em relação à sua identidade.

\section{NARRATIVA IMAGINÁRIA DO HERÓI}

Acerca da relação entre o processo narrativo do indivíduo e a constituição de sua identidade, percebemos a contribuição da imaginação por meio da elaboração mítica do indivíduo como herói de sua narrativa. McAdams (1993) explica, como ato da imaginação, a construção de um mito pessoal que o indivíduo faz em sua narrativa, ao elaborar um cenário ideológico para situar a si como personagem de sua história de vida, com a "criação" de uma história heroica de si mesmo. Esse aspecto mítico não é lenda, mas uma narrativa sagrada que incorpora uma verdade pessoal. Aqui está a contribuição da imaginação no processo de construção da narrativa, por meio do qual o indivíduo produz significados de si.

A imaginação, como sistema psicológico, constitui-se na interfuncionalidade do psiquismo e realiza constantemente novas combinações de imagens, a partir das experiências vividas pelo indivíduo (Vigotski, 2000, 2014; Cruz, 2015). $\mathrm{O}$ processo narrativo conduz o indivíduo a um posicionamento imaginário diante da voz do outro em sua mente (Moghaddam, 1999; Wertsch, 1993). Os posicionamentos materializados ante a voz do outro, no self, utilizam-se também da imaginação para, na narrativa, levarem o indivíduo a se posicionar como docente que pertence a uma categoria profissional (Davies \& Harré, 2007; Oyserman, Elmore, \& Smith, 2012). Nesse momento, ele expande a experiência pela imaginação (Zittoun \& Cerchia, 2013), transitando entre o vivido (passado), o que está vivendo (presente) e o que viverá (futuro).

O mito pessoal, portanto, está relacionado ao posicionamento do indivíduo ante sua narrativa e está vinculado à sua identidade e na construção de seus valores. A personagem da narrativa produz significados do passado e perspectivas para o futuro (McAdams, 1993). Logo, a constituição de nossa identidade se dá no processo dialógico presente na narrativa que desenvolvemos de nós mesmos e que nos coloca como autores de nossas personagens, no jogo de revelação e ocultamento.

McAdams (1993) afirma que a narrativa pode ser constituída de ações que têm como centro a intencionalidade humana. Assim, a identidade pode ser analisada como processo na narrativa pelo qual é possível dizer sobre o indivíduo da ação, 
como processo dirigido a um objetivo consciente (Leontiev, 2004, 2005). Na narrativa com as ações, posicionamentos e negociações do self, o indivíduo, ao narrar sobre sua história de vida, pode se colocar como o herói de sua história (McAdams, 1993), como personagem vencedora das adversidades. O herói da narrativa é uma imagem que o indivíduo tem de si, elaborada pela imaginação. Imagem relacionada a como o indivíduo se percebe.

\section{MÉTODO}

Neste estudo, utilizamos a pesquisa qualitativa, com a abordagem do self dialógico, na perspectiva da Psicologia Cultural. O objetivo foi investigar o processo de constituição da identidade de uma professora. A pesquisa teve como participante uma professora de Biologia, do $6^{\circ}$ ao $9^{\circ}$ ano, de uma escola particular, que cursou licenciatura e bacharelado em Biologia e atuou como professora do ensino fundamental em escola pública e no Programa de Bolsa de Iniciação Científica (PIBID), e que também cursa o mestrado em Ciências Ambientais, a quem atribuímos o nome fictício de Carol. O critério de escolha da professora foi o de atuar em uma escola da educação básica.

Como instrumento de pesquisa, utilizamos a entrevista narrativa audiogravada, em espaço reservado, com a participante. Esta narrou espontaneamente sua história de vida relacionada à questão de ser professora. Para a investigação dos dados, utilizou-se da análise temática dialógica da conversação, pela qual foram identificados os temas e subtemas, as vozes e os turnos da fala na narrativa. A análise teve como foco principal os processos de identidade, narrativa e imaginação.

Para analisarmos o processo de constituição da identidade da professora Carol, pela abordagem do self dialógico na narrativa de sua história de vida, avaliamos primeiramente as contribuições da imaginação na produção de imagens que a professora tem sobre si. Em nossa pesquisa, destacamos duas questôes: a primeira é sobre os posicionamentos identificados em sua narrativa e como eles estão relacionados à atividade docente de Carol; a outra questão é como a imagem de professora heroína, que superou obstáculos na profissão docente, foi elaborada pelo processo da imaginação.

Aentrevista foi gravada, eo áudio transcrito literalmente. Os temas identificados na narrativa foram organizados em uma tabela com os seus respectivos subtemas. Em seguida, elaboramos um mapa semiótico, utilizando como ferramenta o software Xmind6, com o qual articulamos os temas e subtemas no fluxo da narrativa. Para a análise dos dados, buscamos perceber a interação dialógica 
presente na dinâmica da narrativa, por meio da identificação das vozes e seus posicionamentos no self (Davies \& Harré, 2007; Harré \& Van Langenhove, 1999; Moghaddam, 1999).

\section{RESULTADOS E DISCUSSÃO}

A entrevista com a professora Carol apresentou 8 temas e 17 subtemas (quadro 1). Diferentes posicionamentos dotados de vozes estão relacionados a esses temas na narrativa da professora Carol: as vozes de alunos, dos professores, da mãe e a da outra professora de Biologia. A narrativa, como processo dialógico multivocal, é constituída por vozes dos posicionamentos da Carol, com negociações entre ela e os alunos (figura 1).

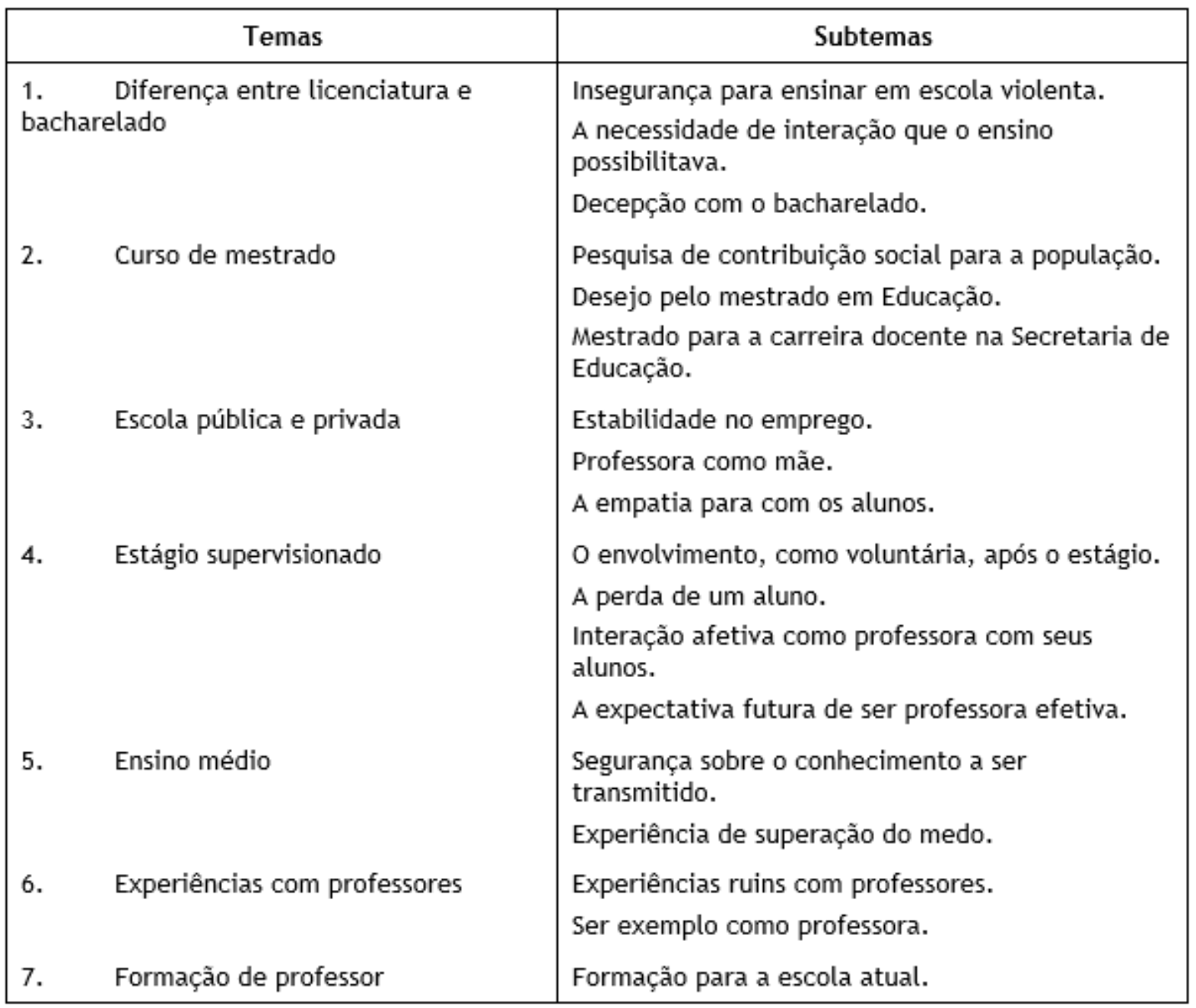

Fonte: elaborado pelos autores.

\footnotetext{
${ }^{1}$ Os temas e subtemas foram retirados da entrevista narrativa com a professora Carol, participante da pesquisa, e não seguem uma ordem linear dos acontecimentos narrados pela participante.
} 
Figura 1 - Mapa semiótico da entrevista da Carol

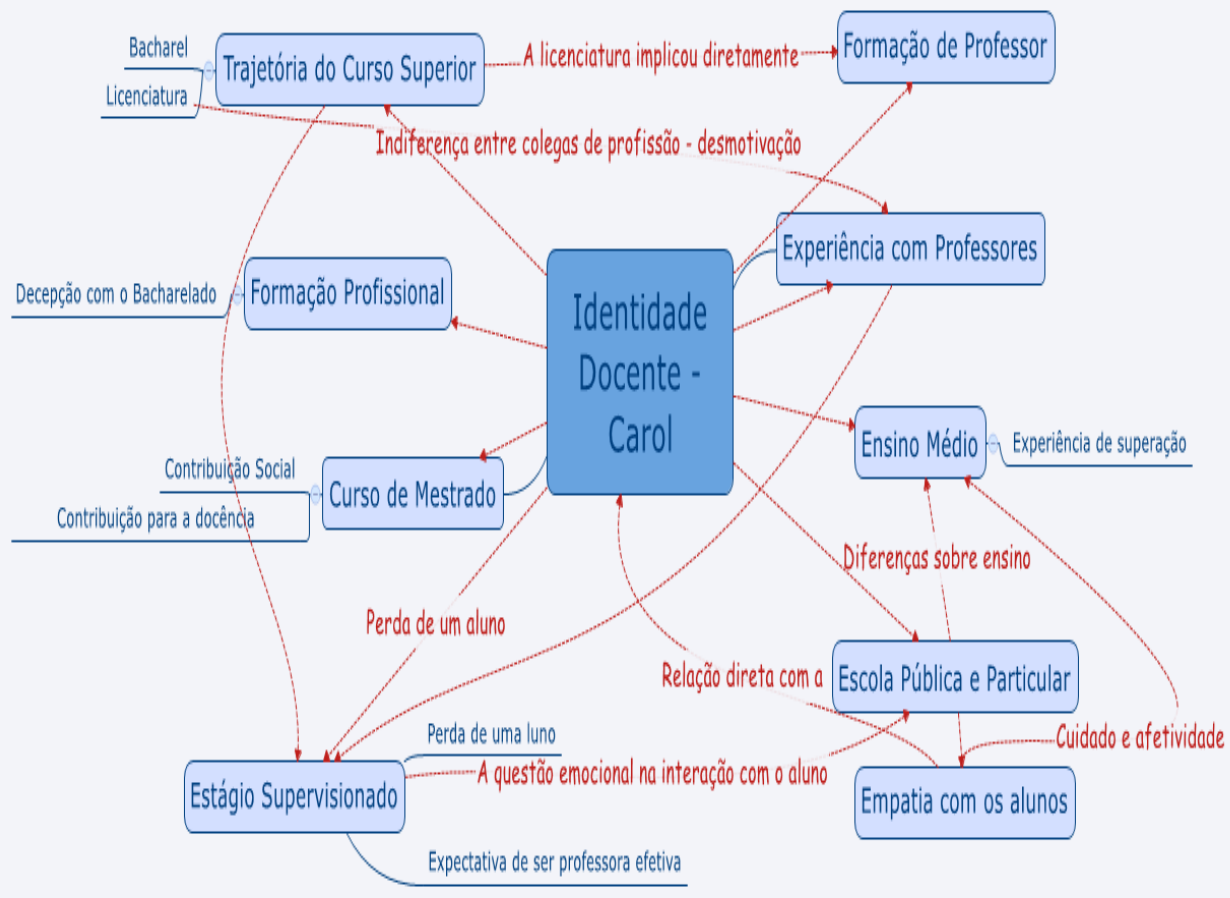

No mapa são articulados os temas e subtemas identificados na narrativa da professora.

Fonte: elaborado pelos autores.

Percebemos que a atividade de Carol como estagiária docente contribuiu para seu posicionamento como professora, ainda que não fosse efetivo, essa experiência começou a traçar características que se incorporariam futuramente em sua profissão, o que segundo (Henry, 2016), pode acontecer quando o indivíduo passa a exercer uma nova atividade diferente da que ele está atuando, no caso de Carol, como estudante. Esse posicionamento de professora participa de negociações com diferentes posiçõos de Carol diante de sua atuação docente. Assim, no processo dinâmico da narrativa, é possível identificar o posicionamento docente, que pode combinar com outro posicionamento, mudar a hierarquia entre eles e até adquirir novos posicionamentos, a depender da atividade e da situação do indivíduo.

Nessa primeira perspectiva, da dinâmica dialógica dos posicionamentos e suas negociaçóes, há um momento em que a professora Carol diz: "Hoje em dia, minha profissão não tá sendo muito legal pra mim [. . .] não tô onde eu queria estar, eu quero tá na rede pública, pela liberdade que a gente tem em sala de aula”. Essa fala se relaciona, na tabela 1, ao tema "escola pública e privada", com seu subtema "estabilidade no emprego", pela professora não encontrar autonomia para desenvolver as atividades docentes com liberdade. Nesse momento da 
narrativa, percebemos o desalinhamento entre o posicionamento profissional da docente e de seu contexto profissional (Arvaja, 2016).

A outra tensão dialógica da Carol foi percebida quando ela diz: "Já tem aquela pressão de que você tem que dar aula pros minino passar no vestibular". Podemos questionar: quem a pressiona? Essa é a questão. O que percebemos na fala da Carol é a tensão entre as vozes da sociedade, que exigem um ensino voltado para o mercado de trabalho, e seu posicionamento como professora. Isso está na tabela 1, no subtema "formação para a escola atual", em que Carol demonstrou ser uma professora preocupada com uma formação docente não tradicional quando afirma: "Os alunos de licenciatura que tão sendo formados por agora tá vindo de uma formação diferente. É óbvio! A gente quer trazer coisas novas, mas tem uma barreira institucional, que não deixa a gente fazer isso".

Essas tensões dialógicas têm caráter social, porque são realizadas mediante significados internalizados das relaçôes sociais (Sigardo, 2000; Vigotski, 2000). Diante disso, quando a professora fala: "Então, se eu tava com os bagunceiros do meu lado, eu tava, tava com tudo", percebemos Carol realizando estratégias de negociação com a turma do ensino médio para conseguir o domínio da turma, o que ela temia não alcançar quando participou do PIBID. Isso porque há uma negociação entre as múltiplas identidades (Anh, 2013), Carol professora e amiga, o que encontramos na sua expressão "bagunceiros do meu lado". Negociação que pode ser identificada entre o posicionamento docente de Carol e os alunos (Henry, 2016). Nessa fala, a professora Carol negocia espaços de ensino.

A relação entre Carol e seus alunos era marcada pela afetividade mediada pelo significado materno. Ela afirma: "Eu cuido deles como se fossem meus filhos [. . .] eu imagino que quando eu tiver filho, eu quero que eles tenham uma professora que cuide deles assim" (Borges, 2007, 2012). Por meio dessa fala, percebemos que ela negocia o significado da sua continuação como professora com o fato de ter um vínculo afetivo com seus alunos, mesmo diante das tensões na sua relação com outros professores da escola, que ignoravam suas iniciativas docentes. Os múltiplos posicionamentos realizam negociações atravessadas por contradições (Akkerman \& Paulien, 2011; Anh, 2013; Arvaja, 2016). Percebemos, em sua fala, uma Carol desmotivada diante da relação com seus colegas professores: "Lá na escola, os, os professores já perceberam que eu dou atenção só pros bagunceiros, só não, né, eu dou mais atenção pros bagunceiros e os problemáticos, que eles chamam de problemáticos", mas que continua na escola, motivada pelo vínculo afetivo com os alunos. Essa relação é apresentada no mapa semiótico (figura 1), entre os temas "trajetória do curso superior" e "experiências com professores". 
Além, contudo, dos múltiplos posicionamentos e suas negociações gerenciadas pelo self, encontramos, na narrativa de Carol, esta como personagem heroica, ao afirmar: "Então, foi super-satisfatório no ensino médio. Quebrou meu medo de ensino médio, que eu tinha muita insegurança de não conseguir ensinar alguma coisa pra eles". Vemos que Carol superou suas dificuldades, neste caso, quanto à sua atuação como professora no ensino médio, quando sua tensão esteve voltada para a capacidade de transmitir o conteúdo didático no PIBID, período que, na narrativa, demonstra sua preocupação quanto ao domínio da turma; e também no ensino fundamental, por sua relação maternal com os alunos. Identificamos isso quando ela afirma: "Quando vejo um aluno dormindo, eu fico: 'caraca, deve tá muito ruim essa aula”. A questão central de sua ocupação como professora é o aluno, é conseguir ensinar de maneira que consiga atrair a atenção na sala de aula. Por isso a empatia com os alunos na escola pública e privada está diretamente ligada à sua interação com eles durante o estágio supervisionado (figura 2).

Figura 2 - 0 processo temático-interativo de Carol com os alunos

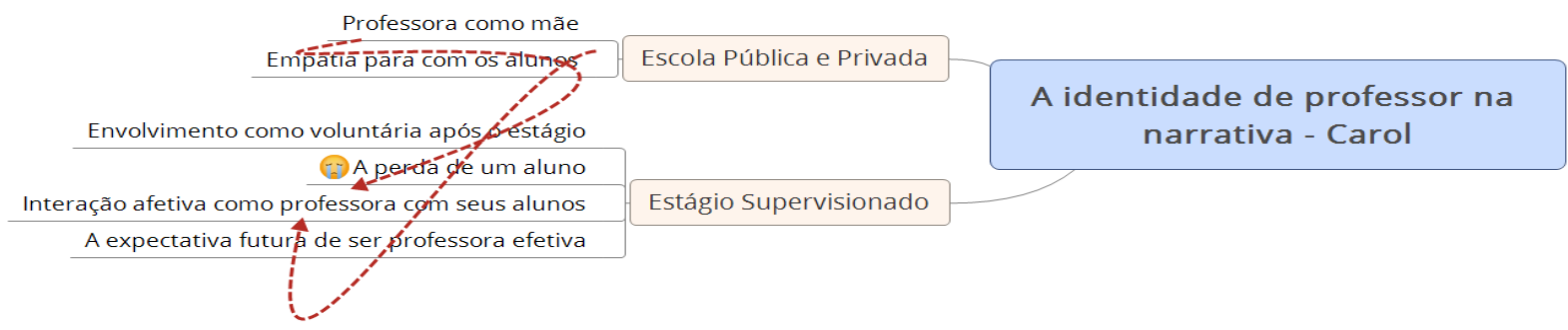

Fonte: elaborado pelos autores.

Nessa ocupação da professora com o discente, foi identificada uma negociação com o aluno, no qual o posicionamento do discente ocupa um valor hierárquico superior. O que percebemos quando ela disse: "Você vai planejar uma aula, cê fica, meu Deus! Fulano, fulano, fulano vai entender, mas os outros não vão, então cê tem que fazer uma média da sua aula", referindo-se à posição para a qual o posicionamento do aluno desloca seu posicionamento docente, em uma negociação atravessada pelo viés moral da responsabilidade de ensinar, e afetivo, pelo cuidado pessoal com eles. No entanto não podemos desconsiderar que o posicionamento docente é único, mesmo em relação dialógica com outros posicionamentos do self, conforme Arvaja (2016), e que se desloca, mas não se confunde com o do aluno. 
Em sua relação com os alunos, a professora Carol se preocupa com as dificuldades de aprendizagem apresentadas no processo de ensino. Acerca disso, Silva, Sirgado e Tavira (2012) reconhecem, de maneira significativa, a interação entre professor e aluno, inclusive com os mais problemáticos, quanto ao comportamento e à conduta de repetência. Carol evidencia esse aspecto da relação com os alunos que apresentaram dificuldade de aprendizagem quando comenta: "Mas eu tento dar o meu melhor, porque eu não posso desistir daquele que tá com dificuldade, que é ele que mais precisa de mim”.

Sobre essa relação professora-aluno, percebemos que, na narrativa de Carol, seu principal estímulo para continuar atuando como professora era a transformação dos alunos. O que fica evidenciado quando afirma: "Com a licenciatura, eu posso salvar vidas [. . .], eu posso salvar vidas na licenciatura, mostrando caminhos diferentes pros alunos". Fala isso se referindo à sua continuidade como professora, o que está em concordância com a pesquisa de Silva et al. (2012), pois a mudança dos estudantes "problemáticos" também foi reconhecida como um dos fatores que explicariam a permanência de professoras na profissão. Nesse sentido, Carol, em sua narrativa, afirma: "Mas eu tento dar o meu melhor, porque eu não posso desistir daquele que tá com dificuldade, que é ele que mais precisa de mim", como já mencionado anteriormente.

Retratados na figura 2, encontramos elementos do processo de interação professor-aluno. Percebemos, pela análise dos dados, que essa interação de caráter afetivo foi articulada pela mediação semiótica nos processos psíquicos, o que resultou no processo de internalização dos significados culturais acerca tanto do ser professora (Cruz, 2011; Holodynski, 2013; Vigotski, 2000, 2014; Zittoun \& Cerchia, 2013; Zittoun \& Gillespie 2013) como o de professoramãe. Esse significado, mãe, é uma metáfora que traz questões sociais sobre a ideia da professora como aquela que tem a responsabilidade materna para orientar a criança. A metáfora é um espaço da linguagem localizado entre o social e o mental (Zittoun, 2008), revelado pelos encontros dialógicos da professora no cotidiano da escola, por meio dos quais foram internalizados significados, que orientaram sua atuação como docente. Identificamos isso quando Carol critica a postura dos pais que deixam seu filho sob o completo cuidado da escola. Ela comenta:

Então eles acham que, na escola, o minino vai aprender tudo sobre a vida, educação, tanto na sociedade quanto intelectual, tudo na escola. Não é bem assim. O papel da família é muito importante na formação de um cidadão e no colégio público. Eles colocam toda essa responsabilidade pra escola e pro professor. Cansei de escutar aluno falando: professora, queria que você fosse minha mãe (Carol). 
Encontramos, nesse turno da narrativa, o processo sociocultural em relação à imagem da professora como mãe. Assim, nos encontros dialógicos, o aluno se identifica com Carol e constrói uma imagem dela como mãe, por associar à professora o perfil materno (Borges, 2007, 2012).

$\mathrm{Na}$ narrativa, acontece uma dinâmica de posicionamentos interdependentes e imaginários, com a transição de identidades nos encontros imaginários e reais (Carbaugh, 1999; Harré \& Van Langenhove, 1999; Moghaddam, 1999), como o aluno na condição de filho e a professora se imaginando mãe. Por meio dessa interlocução, a voz do aluno apresenta o significado de "filho". Por isso, sobre a imagem de mãe, Carol comenta: "Eu gosto muito dos meus alunos, amo todos. Eu cuido deles como se eles fossem meus filhos. Eu não tenho filho ainda, mas eu imagino que, quando eu tiver um filho, eu quero que eles tenham uma professora que cuide deles assim".

Esse vínculo afetivo aparece com clareza em um episódio que foi marcante para Carol, a morte de um aluno, a quem ela caracterizou como dedicado e esforçado nos estudos (figura 3). Isso aconteceu quando ela atuava no ensino fundamental, em escola pública, momento no qual um de seus alunos, ao sair de um clube, recebeu um tiro em meio a um conflito de gangues. Carol, ao falar sobre isso, emociona-se, desencadeando assim uma elaboração de significados sobre ser professora, a partir da experiência com esse evento traumático, considerando, inclusive, sua postura "materna" em relação aos alunos.

Figura 3 - Aspecto do mapa semiótico da experiência emocional de Carol

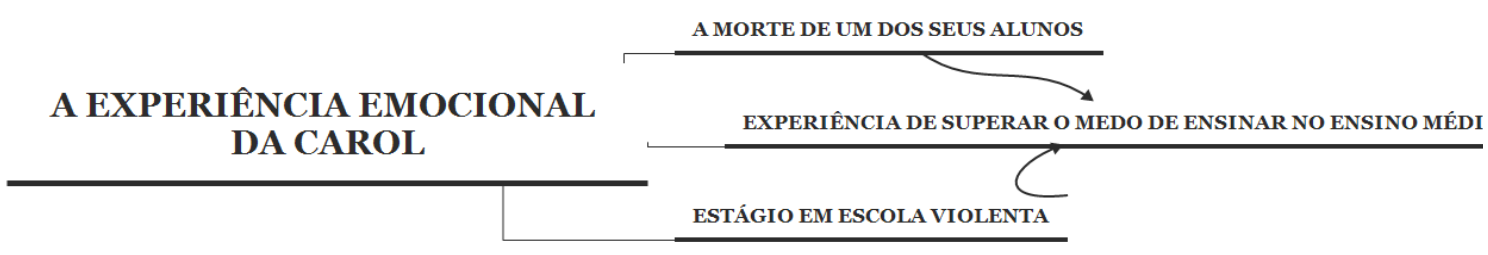

Fonte: elaborado pelos autores.

A experiência sobre a morte de seu aluno evidencia o posicionamento da professora mediante um processo de emoção que aconteceu e encontra-se diretamente vinculado à sua constituição profissional. Ao que ela diz: "Então, para mim, cheguei no auge do que eu poderia chegar como professora [...]. Eu já passei pela experiência de perder um aluno". Logo, a morte de um de seus alunos foi um episódio marcante para Carol. A experiência vivida catalisou seu processo semiótico de construção de significados sobre ser professora. Esse peso emocional 
provocou uma valência, como tendência de combinação de elementos, por meio da qual ocorre a síntese de uma nova realidade semiótica, promovendo novos caminhos imaginados (Zittoun \& Gillespie, 2013). Elementos como a morte do aluno, a insegurança diante da violência na escola e sua responsabilidade moral, e afetividade para com os alunos produziram-lhe uma nova perspectiva profissional como professora (figura 3).

Esse processo mostra como, a partir da densidade emocional de uma experiência, são produzidos novos significados. A partir da participação nos processos de produção de significados, constituímos nossa identidade (Nicolau, Abath, Laranjeira, \& Moscoso, 2010). O aspecto emocional de Carol pode ser visto no mapa semiótico, na ligação de perder um aluno entre o núcleo de identidade docente e o tema estágio supervisionado, como marcador temporal da constituição de sua identidade como professora. No mapa semiótico, os temas e subtemas estão relacionados à "identidade docente como núcleo".

O que encontramos é, assim como a morte de um dos seus alunos, a superação do medo de ensinar no ensino médio, devido à insegurança de não conseguir transmitir os conteúdos necessários e à violência na escola, que enfrentou durante o PIBID, foram fatores que afetaram emocionalmente a professora Carol. Experiência que, pela relação com os alunos, foi internalizada, condição necessária para a presença dos eventos da narrativa na memória.

As experiências no contexto escolar provocaram uma mudança de valores na professora. Percebemos que, no término do estágio docente, o self gerenciou rupturas e transições semióticas na vida da professora Carol, com o processo de organização hierárquica dos valores em seu psiquismo. Valores nascidos das experiências vividas e por meio dos quais ela elaborou uma nova perspectiva sobre si. Assim, ela passa a desenvolver seu significado como docente, principalmente ao esquematizar cognitivamente essas experiências escolares no processo da narrativa (Atkinson, 1998; Polkinghorne, 1998).

A mudança dos valores de Carol é percebida em sua expressão emocional, ao narrar o episódio da morte do aluno e dizer: "Ninguém morreu, só ele, e a escola. Aí eu me emociono um pouquinho". Nesse momento, quem a entrevista diz: "Calma". Identificamos, neste turno da fala, com essa expressão, a tentativa de tranquilizar a entrevistada na conversação, por ter demonstrado muita emoção, situação diante da qual diz: "Que eu gostava muito dele, ele era um aluno muito dedicado".

Ser dedicado é a imagem que construiu como acabamento estético de seu exaluno, pelo que significava para ela, o que ocorreu quando ela conteve e reuniu o outro em sua imagem externa (Bakhtin, 2015). O posicionamento de Carol 
como professora é vinculado afetivamente a seus alunos e conflita também com a posição de outros professores indiferentes a eles. $\mathrm{Na}$ crítica que faz aos docentes que não se importavam com os alunos, percebemos a voz de outros professores quando diz: "Lá na escola, os, os professores já perceberam que eu dou atenção só pros bagunceiros, que eles chamam de problemáticos".

Não desistir do aluno e dar o seu melhor são os alvos da professora. Identificamos isso quando ela se refere às suas experiências com sua professora de Biologia do ensino médio. Carol afirma: "Quero ser igual a ela, porque ela é dedicada, ela é organizada, ela tem paciência”. A imagem de uma boa professora, elaborada pela sua imaginação, com base em suas experiências como aluna, tem um caráter moral pela implicação ética de "ser boa".

A narração da professora também apresentou seu mito pessoal de ser boa professora. Esse mito participa da narração como posicionamento do indivíduo como herói de sua história. A professora apresentou seus medos e inseguranças diante da escola violenta e de alunos problemáticos, desafios que superou no processo narrativo, como ela disse: "Eu tinha muita insegurança de não conseguir ensinar alguma coisa pra eles, porque o aluno adolescente gosta de testar". Esse era um desafio que provocava seu posicionamento diante da expectativa das aulas. Ela vivia, no self, o diálogo sobre a expectativa futura da aula para o aluno, o que percebemos nesta afirmação: "Você vai planejar uma aula, cê fica, meu Deus, fulano, fulano e fulano vai entender, mas os outros não vão". Essas falas de Carol mostram como suas relações sociais implicam a atuação docente mediante a organização de seu psiquismo e desenvolvem os processos da emoção, atribuindo significado especial ao aluno (Magiolino, 2014). Se o aluno estiver ausente do espaço físico, o planejamento da aula ocorre por meio do processo da imaginação, no qual a professora ficava imaginando se o aluno iria entendê-la.

A professora imaginava como iria ensinar. Ocorria no self uma dinâmica imaginária sobre os alunos, com a antecipação do futuro baseada nas experiências vividas no passado e que tinham significação identitária para ela no presente. Isso ocorria por meio de relações dialógicas com o movimento dos posicionamentos do self, pois a narrativa da história de vida, na perspectiva do self dialógico, é concebida como uma matriz de identidade (D'Alte, Petracchi, Ferreira, Cunha, \& Salgado, 2007; Raggatt, 2006). Os posicionamentos ocupam diferentes espaços físicos e metafóricos localizados no self e estão relacionados à identidade (Beijaard, Meijer, \& Verloop, 2004). Assim, os diversos posicionamentos de Carol mudaram em seu self de acordo com a relação dialógica. Os posicionamentos foram identificados na narrativa e constituíram a identidade de Carol como professora. 


\section{CONSIDERAÇÕES FINAIS}

A pesquisa que realizamos teve como objetivo identificar o processo de constituição identitária de uma professora. Para isso, consideramos os processos da narrativa e imaginação. $\mathrm{Na}$ realização da pesquisa, foram tomados os devidos cuidados éticos para a entrevista não ser invasiva no que se refere às questôes que foram surgindo, além do uso de pseudônimo para garantir o anonimato da participante e de sua autorização prévia para a entrevista, levando em consideração o uso dos dados para fins de pesquisa.

$\mathrm{Na}$ narrativa da professora Carol, analisamos os posicionamentos que esta assumiu durante o estágio docente, as negociações que realizou no processo dialógico com os alunos, a relação entre seu posicionamento docente e o contexto profissional de sua atuação como professora. Ponderamos também o que ocorreu relacionado à sua experiência como professora no estágio e em situações dialógicas com os alunos.

As experiências da professora Carol, no processo dialógico com os alunos, trouxeram como consequências uma nova orientação semiótica de suas açóes docentes, ao possibilitarem que ela assumisse um posicionamento imaginário de si como professora no futuro. Também implicaram na regulação de seu pensamento e linguagem para novas relações dialógicas com os alunos e na produção de novos significados relacionados à sua atuação docente, com destaque para o valor afetivo da sua interação com os alunos, inclusive com alunos bagunceiros, em relação ao significado de professora-mãe. Afetividade que se destaca ao narrar o episódio da morte de um aluno.

Como um dos resultados da pesquisa, percebemos um desalinhamento entre o posicionamento docente da professora e seu contexto profissional, o que implica um conflito psíquico. Além disso, também ocorre uma dinâmica mútua entre os posicionamentos de Carol. Por ser uma investigação com uma professora, pode contribuir em pesquisas sobre constituição da identidade docente de mulheres, ao possibilitar a identificação, em pesquisas futuras, de possíveis diferenças entre os processos de constituição identitária docente entre professoras e professores. No processo narrativo de Carol, identificamos tensões dialógicas entre as vozes dos posicionamentos em relação a processos socioculturais. Também encontramos na narrativa da professora sua imagem como heroína, mediante as experiências de superação dos desafios como docente.

Diante da discussão apresentada, corroboramos com a constituição da identidade docente como processo dialógico entre os posicionamentos do self que emerge da relação entre a professora e os alunos. Sugerimos, para futuras pesquisas, a investigação de como a imaginação combina as imagens sobre 
docência na narrativa dos participantes. Ao propormos a análise dos conceitos de identidade, narrativa e imaginação, nós os consideramos como processos psíquicos para a viabilidade da abordagem dialógica do self no estudo da constituição identitária docente. 


\section{REFERÊNCIAS}

Akkerman, S. F., \& Paulien, C. M. (2011). Dialogical approach to conceptualizing teacher identity. Teaching and Teacher Education, 27, 308-319.

Anh, D. T. K. (2013). Identity in activity: examining teacher professional identity formation in the paired-placement of student teachers. Teaching and Teacher Education, 30, 47-59.

Arvaja, M. (2016). Building teacher identity through the process of positioning. Teaching and Teacher Education, 59, 392-402.

Atkinson, R. (1998). The life story interview. Thousand Oaks: Sage.

Bakhtin, M. M (2015). Estética da criação verbal. P. Bezerra (Trad.). São Paulo: WMF Martins Fontes.

Beijaard, D., Meijer, P. C., \& Verloop, N. (2004). Reconsidering research on teachers' professional identity. Teaching and Teacher Education, 20(2), 107128.

Borges, F. T. (2007). Posicionamentos do ser professora mediados pela leitura da novela e do filme brasileiro. In Anais, 16 Congresso de Leitura do Brasil, Campinas. Campinas: Associação de Leitura do Brasil, Unicamp.

Borges, F. T. (2012). A professora que vemos nos filmes: construção identitária e significados da docência. Caderno CEDES, 32(88), 303-317.

Carbaugh, D. (1999). Positioning as display of cultural identity. In R. Harré, \& L. Van Langenhove. (Eds.), Positioning Theory. (pp. 160-177). Oxford: Blackwell.

Cruz, M. N. (2011). Imaginação, linguagem e elaboração de conhecimento na perspectiva da psicologia histórico-culturalde Vigotski. A. L. B. Smolka; A. L. H. Nogueira (Eds.), Emoção, memória, imaginação: a constituição do desenvolvimento humano na história e na cultura. Campinas: Mercado de Letras.

Cruz, M. N. (2015). Imaginário, imaginação e relações sociais: reflexões sobre a imaginação como sistema psicológico. Centro de Estudos Educação e Sociedade, 35(núm. especial), 361-374. 
D’Alte, I., Petracchi, P.; Ferreira, T., Cunha, C., \& Salgado, J. (2007). Self dialógico: um convite a uma abordagem alternativa ao problema da identidade pessoal. Interaçôes, 6, 8-31.

Davies, B., \& Harré, R. (2007). Positioning: the discursive production of selves. Journal for the Theory of Social Behaviour, 20, 43-63.

Harré, R., \& Van Langenhove, L. (Orgs.). (1999). Positioning theory. Massachusetts: Blackwell.

Henry, A. (2016). Conceptualizing teacher identity as a complex dynamic system: the inner dynamics of transformations during a practicum. Journal of Teacher Education, 67(4), 291-305.

Hermans, H. J. M. (2015). Dialogical self in a complex world: the need for bridging theories. Europe's Journal of Psychology, 11(1), 1-4.

Holodynski, M. (2013). The internalizations theory of emotions: a cultural historical approach to the development of emotions. Mind, Culture and Activity, 20(1), 4-38.

Huang, I-C. (2014). Contextualizing teacher identity of non-nativeenglishspeakers in U.S. secondary ESL classrooms: a Bakhtinian perspective. Linguistics and Education, 25, 119-128.

Leontiev, A. N. (2004). O desenvolvimento do psiquismo. (2a ed.). São Paulo: Centauro.

Leontiev. A. N. (2005). The genesis of activity. Journal of russian and east european psychology, 43(4), 58-71. Recuperado a partir de http://www.tandfonline.com/ doi/pdf/10.1080/10610405.2005.11059253?needAccess=true

Magiolino, L. L. S. (2014). A significação das emoções no processo de organização dramática do psiquismo e de constituição social do sujeito. Psicologia \& Sociedade, 26(2), 48-59.

McAdams, D. P. (1993). The stories we live by. New York, London: The Guilford Press.

Moghaddam, F. M. (1999). Reflexive positioning: culture and private discourse. In R. Harré, \& L. Van Langenhove (Eds.), Positioning theory. (pp. 74-86). Massachusetts: Blackwell. 
Nicolau, M., Abath, D., Laranjeira, P. C., \& Moscoso, T. (2010). Comunicação e Semiótica: Visão geral e introdutória à semiótica e de Peirce. Revista Eletrônica Temática, 6(8).

Oyserman, D., Elmore, K., \& Smith, G. (2012). Self, self-concept, and identity. In M. R. Leary, \& J. P. Tangney (Eds.), Handbook of self and identity. (pp. 69104). New York, London: The Guilford Press.

Polkinghorne, D. E. (1988). Narrative knowing and the human sciences. New York: State University of New York.

Raggatt, P. T. F. (2006). Multiplicity and conflict in the dialogical self: A lifenarrative approach. In D. P. McAdams, R. Josselson \& A Lieblich (Eds.). Identity and story: creating self in narrative. (pp. 15-35). Washington: American Psychological Association.

Riessman, C. K. (1993). Narrative analysis. Newbury Park: Sage.

Sigardo, A. P. (2000). O social e o cultural na obra de Vigotski. Educação \& Sociedade, 21(71), 45-78.

Silva, D. N. H., Sirgado, A. P., \& Tavira, L. V. (2012). Memória, narrativa e identidade profissional: analisando memoriais docentes. Caderno Cedes, 32(88), 263-283.

Valsiner, J. (2006). Culture in minds and societies: foundations of cultural psychology. Worcest: Sage.

Vigotski, L. S. (2000). A construção do pensamento e da linguagem. P. Bezerra (Trad.). São Paulo: Martins Fontes.

Vigotski, L. S. (2014). Imaginação e criatividade na infância. J. P. Fróis (Trad.). São Paulo: WMF Martins Fontes.

Wertsch, J. W. (1993). Voices of the mind: a sociocultural approach to mediated action. Cambridge: Harvard University Press.

Zittoun, T. (2008). Learning through transitions: the role of institutions. European Journal of Psychology of Education, 23(2), 165-181.

Zittoun, T., \& Cerchia, F. (2013). Imagination as Expansion of Experience. Integrative Psychological and Behavioral Science, 47, 305-324.

Zittoun, T., \& Gillespie, A. (2013). Internalization: how culture becomes mind. 